\title{
CARACTERIZAÇÃo QUÍMICA PARCIAL DA SEMENTE DE JATOBÁ-DO-CERRADO (Hymenaea stigonocarpa Mart.)
}

\author{
Tatiana G. MATUDA ; Flavia MARIA NETTO
}

\begin{abstract}
RESUMO
Este trabalho teve como objetivo a caracterização quimica parcial da semente de jatobá-do-cerrado (Hymenaea stigonocarpa Mart.), a fim de avaliar o potencial de aproveitamento desta espécie e contribuir para a preservação de espécies nativas do cerrado, através da valorização de seus recursos naturais. A semente apresentou alto teor de fibras $(85,31 \%), 9,05 \%$ de proteínas e $5,30 \%$ de lipídios (base seca). A análise de aminoácidos mostrou que a proteína, como outras leguminosas, tem os aminoácidos sulfurados e a treonina como aminoácidos limitantes. A fração lipídica apresentou $75 \%$ de ácidos graxos insaturados, sendo o ácido linoléico dominante $(46,9 \%)$. Dentre os fatores antinutricionais estudados, os compostos fenólicos, com $48 \mathrm{mg} / \mathrm{g}$ de farinha de jatobá desengordurada (base seca), mostraram teor acima do encontrado em outras leguminosas. A semente de jatobá mostrou-se pobre em macronutrinentes quando comparada a leguminosas utilizadas na alimentação, mas o alto teor de fibras, possivelmente constituídas de xiloglucanas e galactomananas, pode levar ao aproveitamento rentável destas sementes.
\end{abstract}

Palavras-chave: jatobá; Hymenaea stigonocarpa Mart.; leguminosas; sementes; composição química.

\section{SUMMARY}

PARTIAL CHEMICAL CHARACTERIZATION OF JATOBÁ-DO-CERRADO SEEDS (Hymenaea stigonocarpa Mart.). The objective of this work was the partial chemical characterization of the jatobá-do-cerrado (Hymenaea stigonocarpa Mart.) seed in order to evaluate the potential value as a food and/or feed source and to contribute to the preservation of Brazilian native species from "cerrado" through valorization of its natural resources. Jatobá-do-cerrado seeds had a high crude fiber content (85.31\%), 9.05\% of crude protein and $5.30 \%$ of total lipids (dry basis). Amino acids analysis showed that protein was deficient in sulfur amino acids and treonin and high in other essential amino acids. Lipid fraction showed $75 \%$ of unsaturated fatty acid and linoleic acid was dominant (46.9\%). Amongst the studied antinutritional factors, total phenolics $(48 \mathrm{mg} / \mathrm{Eg}$ of defatted flour, dry basis)) was higher than in other leguminous seeds. However, despite the fact that this seed showed lower macronutrients content than other legume seeds used as human food, the high fiber content, possibly composed of xiloglucanns and galactomananns could lead to an interesting use of these seeds.

Keywords: jatobá; Hymenaea stigonocarpa Mart.; leguminous seeds chemical composition.

\section{1 - INTRODUÇÃO}

Sementes de leguminosas arbóreas vêm sendo estudadas, tendo em vista sua utilização na alimentação humana ou animal em algumas regiões, em épocas de alimentação escassa, ou ainda como forma de valorização e preservação dos recursos naturais. Sementes de leguminosas arbóreas de diferentes partes do mundo têm sido estudadas, Vicia faba L. da região da Antalya [13], Acacia coleie Acacia tumida, alimentos tradicionais do povo aborígine australiano, Cassia floribunda Cav do sul da Índia [38], Lathyrus maritimus L. característica de praias em países como o Japão e o Canadá [8], Centrosema pubescente, Tamarindus indica e Cassia alata na Nigéria [15, $36,37]$ e leguminosas selvagens do deserto de Sonora, no México [23]. Segundo ORTEGA-NIEBLAS, VÁSQUEZ-

Recebido para publicação em 05/04/2004. Aceito para publicação em 04/05/2005(001325).

Departamento de Alimentos e Nutrição, Faculdade de Engenharia de Alimentos, UNICAMP. R. Monteiro Lobato, 80. CP: 6121. CEP: 13083802, Campinas-SP, Brasil.

A quem a correspondência deve ser enviada.
MORENO \& ROBLES-BURGUEÑO [23], sementes e vagens do gênero Acacia, Olneya e Prosopis têm sido utilizadas em diversos países para consumo humano e animal. BRAVO, GRADOS \& SAURA-CALIXTO [4] demonstraram que vagens de plantas do gênero Prosopis são palatáveis e possuem alto valor nutricional e baixo teor de compostos antinutricionais. No Brasil, TOGASHI \& SGARBIERI [35] estudaram a semente de baru (Dypterix alata Vog), espécie do cerrado brasileiro, concluindo que pode ser uma importante fonte de proteínas e carboidratos.

As sementes de leguminosas também são utilizadas como fonte de galactomananas e xiloglucanas, do grupo das fibras solúveis, por indústrias de alimentos e farmacêutica. As propriedades reológicas das galactomananas e xiloglucanas determinam seu uso como emulsificantes, espessantes e dispersantes. Existem galactomananas de três espécies de sementes produzidas em escala industrial, a goma guar (Cyamopsis tetragonoloba (L.) Taub), goma locusta (C. siliqua) e goma tara (Caesalpinia spinosa L.) que são responsáveis pela terceira maior produção industrial de polissacarídeos (depois da celulose e do amido). A única fonte de xiloglucanas explorada comercialmente é o Tamarindus indica, utilizada em alimentos no Japão [26, 28]. 
O jatobá-do-cerrado, uma leguminosa característica do cerrado brasileiro, é uma planta com 4 a $6 \mathrm{~m}$ de altura que produz frutos com comprimento entre 6 e $18 \mathrm{~cm}$ e diâmetro de 3 a $6 \mathrm{~cm}$. Seus frutos farináceos são comestiveis e muito apreciados pela população regional e podem ser consumidos in natura ou como ingrediente na elaboração de bolos, pães e mingaus, cookies e snacks com alto teor de fibras [6, 29, 30].

A semente de Hymenaea courbaril apresenta em sua composição xiloglucanas e galactomananas, principais hemiceluloses encontradas na parede celular de plantas dicotiledôneas, utilizadas na fabricação de papéis assim como a goma guar e o amido [20]. No entanto, não foram encontrados na literatura trabalhos sobre a caracterização da semente do jatobá-do-cerrado. O presente trabalho teve como objetivos a caracterização química parcial desta semente, incluindo a determinação de sua composição em aminoácidos e ácidos graxos e o estudo da presença de fatores antinutricionais.

\section{2 - MATERIAL E MÉTODOS}

As sementes estudadas, enviadas e identificadas pela Prof ${ }^{a} D^{a}$ Julia Geracila de Mello, da Universidade Federal do Piauí, foram obtidas na cidade de José de Freitas-PI. Por serem extremamente duras, foi necessária a quebra mecânica das sementes para a obtenção da farinha, após congelamento em nitrogênio líquido. As sementes (aproximadamente $3 \mathrm{~kg}$ ) foram, então, moídas em moinho de rotor e martelos fixos, modelo MA 090 Marconi Equipamentos para Laboratório LTDA (Brasil) e a farinha obtida em peneira de 60mesh foi utilizada nas análises químicas e bioquímicas.

A análise em fotomicroscópio ótico (Olympus CBA, Tóquio, Japão), empregando filme colorido comercial ASA 100, foi realizada para indicar qualitativamente a composição da semente [12, 21]. Cortes finos da ordem de micrômetros $(\mu \mathrm{m})$ do tecido da semente foram deixados em suspensão em solução contendo glicerol e água. Um corte em suspensão foi colocado sobre lâmina histológica sem adição de corantes, sendo o mesmo procedimento repetido para outras placas, no entanto nestas acrescentou-se solução alcoólica de Sudan IV para coloração das gotículas de óleo, Coumassie em solução de mistura acético-alcoólica para coloração de proteina.

Os teores de umidade, cinzas e nitrogênio foram determinados segundo a AOAC [1]. Para determinação do teor de proteína, o teor de nitrogênio foi multiplicado pelo fator 5,8 , utilizado para proteínas de leguminosas. Os lipídios totais foram determinados pelo método descrito por BLIGH \& DYER [3].

O teor de fibras totais foi determinado por método enzímico-gravimétrico [24], utilizando as enzimas alfaamilase, alcalase 0,6L e amilo-glicosidase. (Novo Nordisk Biochem Inc, Dinamarca).

Fenóis totais foram determinados conforme metodologia proposta por BUDINI, TONELLI \& GIROTTI [5], base- ada na formação do complexo azul da Prússia. Foi utilizada a catequina (Sigma Aldrich, St. Louis, USA) como referência para curva padrão e os resultados foram expressos em mg de equivalente em catequina/g de amostra.

Os inibidores de tripsina foram determinados pelo método proposto por KAKADE et al. [17], utilizando o substrato sintético BAPNA (hidrocloreto de nafta-benzoil - DL - argenina - $\mathrm{p}$ - nitroanilida) (Sigma).

A hemaglutinina foi determinada de acordo com JUNQUEIRA \& SGARBIERI [16], metodologia baseada na observação da aglutinação de hemáceas tripsinizadas de coelho, a 4\% quando em presença de fitohemaglutinina. A análise de aminoácidos foi realizada em analisador de aminoácidos P4000, com reator PCX3100 (Pickering Laboratories, Mountain View, CA, USA). Para esta análise a farinha foi submetida previamente à hidrólise ácida com $\mathrm{HCl} 6 \mathrm{~N}$ a $110^{\circ} \mathrm{C}$ por $22 \mathrm{~h}$.

Os ácidos graxos foram determinados por cromatografia gasosa, e os ésteres metílicos dos ácidos graxos foram obtidos de acordo com HARTMAN \& LAGO [14], utilizando o cromatógrafo a gás VARIAN 3600 (Walnut Creek, CA, USA) e coluna capilar (J\&W Scientific, Folsom, CA, USA), com fase líquida DB-WAX, filme de $0,25 \mu \mathrm{m}$ de espessura e dimensões de $30 \mathrm{~m}$ de comprimento por $0,252 \mathrm{~mm}$ de diâmetro interno. A temperatura da coluna foi programada com temperatura inicial de $170^{\circ} \mathrm{C}$ e temperatura final de $210^{\circ} \mathrm{C}$ numa razão de $1^{\circ} \mathrm{C} / \mathrm{min}$, sendo a temperatura do injetor de $250^{\circ} \mathrm{C}$ e a vazão de gás de arraste - hidrogênio de $1 \mathrm{~mL} / \mathrm{min}$. Os ácidos graxos foram identificados por comparação com padrões. Para a extração dos ácidos graxos da amostra, utilizou-se a técnica descrita por BLIGH \& DYER [3], modificado por ESTEVES et al .[10].

\section{3 - RESULTADOS E DISCUSSÃO}

A avaliação da microestrutura da semente foi realizada para uma análise qualitativa preliminar da composição das sementes. As micrografias dos tecidos estão apresentadas na Figura 1. Observa-se que a parede celular apresentou-se espessa enquanto que a quantidade presente de grânulos de amido foi muito escassa (Figuras 1a e 1b). A presença de lípides e proteína, evidenciada por reação cm Sudan e Comassie, respectivamente (Figuras 1 c e $1 d$ ), mostrou-se relativamente esparsa quando comparados à grande espessura das paredes celulares.

Os dados da composição química aproximada estão apresentados na Tabela 1 . O teor protéico $9,05 \mathrm{~g} / 100 \mathrm{~g}$ de amostra é baixo quando comparado aos observados para leguminosas asiáticas, Vigna mungo L. Hepper $(21,9 \mathrm{~g} / 100 \mathrm{~g}$ de amostra) e Cicer arietinum $(25,5 \mathrm{~g} / 100 \mathrm{~g}$ de amostra) [27], mexicanas Albizzia lebbek (33,7g/100g de amostra) e a Gliricidia sepium $(43,3 \mathrm{~g} / 100 \mathrm{~g}$ de amostra) ou brasileira Dypterix alata, $\operatorname{Vog}(30 \mathrm{~g} / 100 \mathrm{~g}$ de amostra) [35]. Algumas espécies silvestres do deserto de Sonora [23] que variaram de 19,5\% para Olneya tesota a 30,1\% para Mimosa grahamii e de leguminosas tradicio- 
TABELA 1 - Composição química aproximada da farinha de semente de jatobá

\begin{tabular}{lc}
\hline & $\mathrm{g} / 100 \mathrm{~g}$ de sólidos \\
\hline Umidade $^{1}$ & $10,18 \pm 0,07$ \\
Cinzas $^{1}$ & $1,80 \pm 0,03$ \\
Proteína $^{1}$ & $9,05 \pm 0,07$ \\
Lipidios $^{1}$ & $5,3 \pm 0,2$ \\
Fibras Totais $^{2}$ & 85,31 \\
\hline
\end{tabular}

1 Média \pm desvio padrão de 3 determinações

2 Média de 2 determinações

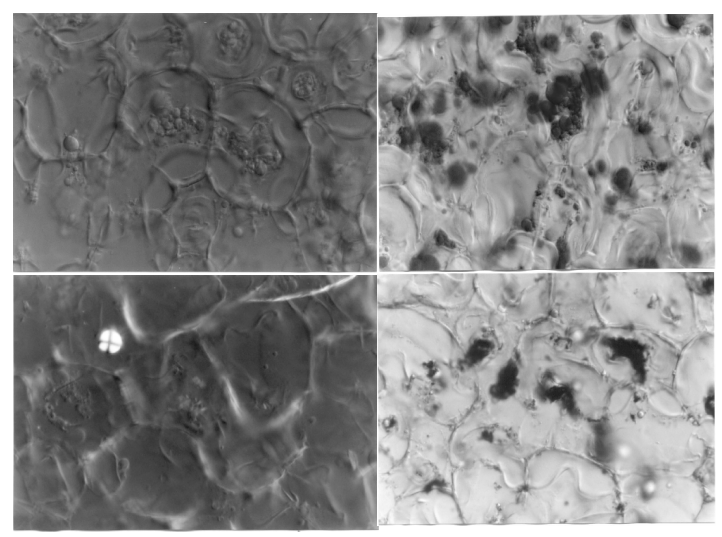

FIGURA 1 - (a) Corte da semente de jatobá sem corante, apresentando o conteúdo vacuolar; )b) corte da semente sem corante, com luz polarizada, mostrando um raro grão de amido; (c) corte da semente com corante Sudan, que permite visualização das gotícolas de óleo; (d) corte com corante Comassie que permite visualização de proteínas da semente de jatobá

nalmente utilizadas na alimentação como a soja (38 a 44\%) [31]. Outras leguminosas mexicanas, no entanto, apresentam teor protéico mais próximo ao da semente de jatobá estudada, Hymenaea courbaril $(10,6 \mathrm{~g} / 100 \mathrm{~g}$ de amostra) e Cymbopetalum penduliflorum $(11,3 \mathrm{~g} / 100 \mathrm{~g}$ de amostra) [32].

O teor lipídico total foi $5,3 \mathrm{~g} / 100 \mathrm{~g}$ de solidos, inferior ao apresentado pelas sementes do Deserto de Sonora os quais variaram de 8,5 (Parkinsonia aculeata) a 23,5g/100g de amostra (Mimosa grahamii) [23] e de algumas leguminosas mexicanas como Hymenaea courbaril $(8,59 \mathrm{~g} / 100 \mathrm{~g}$ de amostra) e Caesalpinia pulcherrima $(25,11 \mathrm{~g} / 100 \mathrm{~g}$ de amostra [32] ou ainda da Dypterix alata, $\operatorname{Vog}(40,3 \mathrm{~g} / 100 \mathrm{~g}$ de amostra [35]. O valor obtido ficou próximo aos apresentados pelas leguminosas asiáticas reportados por SATHE [27] que variaram entre 1,2a $6,0 \mathrm{~g} / 100 \mathrm{~g}$ de amostra para Vigna radiata (L.) R. Wilczek e Cicer arietinum L., respectivamente, e Cassia floribun$d a(2,1$ a 3,1g/100g de amostra) [38].

O teor de fibras totais, $85,31 \mathrm{~g} / 100 \mathrm{~g}$ de sólidos, foi muito superior ao das sementes de leguminosa arbórea do deserto de Sonora, Olneya tesota, 6,5g/100g de amostra [23], ao de leguminosas tradicionais como a soja $(2,4$ a $5,5 \mathrm{~g} / 100 \mathrm{~g}$ de amostra) e a lentilha $(3,8$ a 4,6 g/ $100 \mathrm{~g}$ de amostra) [25], ou mesmo superior aos valores apresentados por fontes tradicionais de fibras alimentares como o farelo de aveia e o de trigo com níveis de 20,4 e $49,5 \mathrm{~g} / 100 \mathrm{~g}$ de amostra respectivamente [7]. Xiloglucanas e galactomananas são os polissacarídeos de armazenamento predominantemente presentes em tecidos do cotilédone de diversas espécies, entre elas outra espécie de jatobá, a Hymenaea courbaril, que apresenta $40 \%$ de xiloglucanas em sua composição [20]. As galactomananas, classificadas como fibras solúveis, pertencem ao grupo de aditivos de alimentos biologicamente ativos, sendo utilizadas na formulação de produtos dietéticos ou terapêuticos. São ainda utilizadas na indústria farmacêutica, de cosméticos e de papel [28]. A farinha da semente de jatobá mostrou-se altamente viscosa em meios ácido, alcalino e tamponado, dificultando a execução de algumas análises, que pode ser indicativo da presença de gomas. A ausência observada dos carboidratos e o alto teor de fibras confirma o que foi observado na Figura $1 a$, onde se verifica um número extremamente reduzido de grânulos de amido. O baixo teor de lipídios e de proteínas das sementes de jatobá também confirmaram a análise qualitativa da microestrutura.

Na composição em ácidos graxos da semente de jatobá o ácido linoléico, que é um ácido graxo essencial, apresentou-se dominante $(46,88 \%)$, seguido do ácido oléico $(28,07 \%)$ (Tabela 2). O teor de ácidos graxos insaturados foi de aproximadamente $87 \%$, valor superior aos encontrados para o feijão Phaseolus vulgaris $(67,8 \%)$ e para a soja Glycine max (64,9\%) [22]. Foram também observadas quantidades traço de ácidos graxos de cadeia longa, que não puderam ser identificados.

O perfil de aminoácidos da farinha da semente de jatobá (Tabela 3), mostrou altos teores na maioria dos aminoácidos essenciais, quando comparados ao recomenda-

TABELA 2 - Composição em ácidos graxos da fração lipídica da semente dejatobá

\begin{tabular}{lc}
\hline Ácidos Graxos & $\%$ \\
\hline Palmítico (16:0) & $\mathbf{8 , 9}$ \\
Esteárico (18:0) & 4,7 \\
Oléico (18:1 (n-9)) & 31,6 \\
Linoléico (18:2 (n-6)) & 52,8 \\
Linolênico (18:3 (n-3)) & 1,2 \\
Eicosanoico (20:0) & 0,8 \\
Saturados & 14,4 \\
Insaturados & 85,6 \\
\hline Valores são médias de duas extrações &
\end{tabular}

do pela FAO/WHO [11]. Os aminoácidos deficitários comparados ao padrão são os sulfurados (metionina + cisteína) e treonina, sendo os sulfurados os aminoácidos limitantes, com escore químico de $78,24 \%$. Aminoácidos sulfurados são limitantes na maioria das leguminosas e o valor obtido para a semente de jatobá foi próximo do relatado para soja, $84 \%$, e superior ao reportado para outras leguminosas como Vicia faba (56\%) e Vigna sinensis [2]. Os teores de lisina e fenilalanina+tirosina foram mais eleveados do que o padrão de referência da FAO assim como diversas outras leguminosas arbóreas ou outras tradicionalmente cultivadas [32, 34]. 
Os compostos fenólicos apresentaram valor de $48 \pm 2 \mathrm{mg}$ de catequina/g de amostra de farinha desengordurada (base seca). Este valor foi maior que os apresentados por outras leguminosas tais como da Vigna mungo, e da Vigna radiata L., 8,66 e $8,08 \mathrm{mg} / \mathrm{g}$ de matéria seca, respectivamente $[18,19]$. Polifenóis apresentam-se mais abundantes em cultivares com casca escura, como a semente de jatobá, do que nas claras, possuem propriedades fungistáticas e podem proteger a semente de invasões de fungos sendo o descascamento muito eficiente para sua redução [33].

TABELA 3 - Composição em aminoácidos da farinha da semente de jatobá e perfil de aminoácidos para uma proteína ideal, segundo recomendações da FAO/WHO [11] para crianças de 2 a 5 anos de idade

\begin{tabular}{lcc}
\hline \multicolumn{1}{c}{ Aminoácidos } & $\begin{array}{c}\text { Farinha da semente } \\
\text { (mg aa/g proteina) }\end{array}$ & $\begin{array}{c}\text { Padrão FAO } \\
\text { (mg aa/g proteína) }\end{array}$ \\
\hline Histidina & 36,21 & 19 \\
Isoleucina & 48,45 & 28 \\
Leucina & 95,45 & 66 \\
Lisina & 73,16 & 58 \\
Metionina + Cisteína & 19,56 & 25 \\
Fenilalanina + Tirosina & 80,29 & 63 \\
Treonina & 31,89 & 34 \\
Triptofano & $\mathrm{Nd}$ & 11 \\
Valina & 56,13 & 35 \\
Escore Químico (\%) & 78,24 & \\
\hline Nd = Não determinado; valores são médias de duas repetições &
\end{tabular}

A qualidade da proteína é afetada, entre outros fatores, por componentes como inibidores de tripsina, fenóis, hemaglutininas, que podem interagir com o trato intestinal e enzimas digestivas, reduzindo a digestibilidade das proteínas e a absorção de aminoácidos [32]. Os inibidores de tripsina apresentaram valores em torno de $17,1 \mathrm{UTI} / \mathrm{mg}$ de amostra, valor superior ao do feijão, 9 a 14UTI/mg [9] e inferior ao da soja que alcança 64UTI/mg da amostra [34]. Este valor é representativo, pois segundo SOTELO, SOUSA \& SANCHEZ [34], 10UTI/mg de amostra é importante sob o aspecto nutricional do alimento. O nivel de atividade do inibidor de tripsina pode ser considerado significativa em termos nutricionais, mas de menor impacto quando comparado aos teores encontrados na soja, no entanto esta atividade pode ser reduzida por tratamento térmico [35]. A semente de jatobá não apresentou atividade hemaglutinante. Apenas uma (Mimosa grahamii), entre sete sementes de leguminosas arbóreas estudas por ORTEGA-NIEBLAS, VÁSQUEZMORENO \& ROBLES-BURGUEÑO [23] não apresentou atividade hemaglutinante. Este fator antinutricional, no entretanto, por ser solúvel em soluções salinas pode ser removido por maceração [23].

\section{4 - CONCLUSÕES}

A semente de jatobá apresentou alto teor de fibras totais, baixo teor de proteínas e lipídios. A proteína comparada ao padrão da $\mathrm{FAO} / \mathrm{WHO}[10]$ mostrou-se deficitária nos aminoácidos sulfurados. A fração lipídica apresentou predominância de $86 \%$ em ácidos graxos insatura- dos. A semente de jatobá mostrou-se pobre em macronutrinentes quando comparada a leguminosas utilizadas na alimentação, mas o alto teor de fibras, possivelmente constituídas de xiloglucanas e galactomananas, pode levar ao aproveitamento rentável destas sementes, sendo necessárias pesquisas sobre sua composição e aplicações. A dureza da semente pode ser um obstáculo a ser vencido numa eventual tentativa de aproveitamento desta semente.

\section{5 - REFERÊNCIAS BIBLIOGRÁFICAS}

[1] AOAC (ASSOCIATION OF OFFICIAL ANALYTICAL CHEMISTS). Official methods of analysis of the Association of Official Analytical Chemists. 15th ed. Washington, DC., 1990.

[2] AHMED, A.H.R.; NOUR, A.A.M. Protein quality of common Sudanese leguminous seeds. Lebensm.-Wiss. U.- Technol., v.23, p.301-304, 1990. Bligh, E. G.; Dyer, W. J. A rapid method of total lipid extraction and purification. Can. J. Biochem. Physiol., v. 37, n. 8, p. 911-917, 1959.

[3] BLIGH, E.G.; DYER, W.J. A rapid method of total lipid extraction and purification. Can. J. Biochem. Physiol., v. 37, n.8, p.911-917, 1959.

[4] BRAVO, L.; GRADOS, N.; SAURA-CALIXTO, F. Composition and potential uses of mesquite pods (Prosopis pallida L): comparison with carob pods (Ceratonia siliqua L.). J. Sci. Food Agric., v. 65, n.3, p. 303-306, 1994.

[5] BUDINI, R.; TONELLI, D.; GIROTTI, S. Analysis of total phenols using the Prussian blue method. J. Agric. Food Chem., v. 28, n. 6, p. 1236-1238, 1980.

[6] CHANG, Y. K.; SILVA, M. R.; GUTKOSKI, L. C.; SEBIO, L.; SILVA, M. A. A. P. Development of Extruded Snacks Using Jatoba (Hymenaea stigonocarpa Mart) Flour and Cassava Starch Blends. J. Sci. Food Agric., v. 78, n. 1, p. 59-66, 1998.

[7] CHAUDHARY, V. K.; WEBER, F. E. Barley bran flour evaluated as dietary fiber ingredient in wheat bread. Cereal Food World, v. 35, n. 6, p. 560-562, 1990.

[8] CHAVAN, U. D.; SHAHIDE, F.; BAL, A. K.; McKENZIE, D. B. Physico-chemical properties and nutrient composition of beach pea (Lathyrus maritimus L.). Food Chem., v. 66, n. 1, p. 43-50, 1999.

[9] Elias, L. G., DE FERnANDEZ, D. G., BRESSANI, R. Possible effects of seed coat polyphenolics on the nutritional quality of bean protein. J. Food Sci., v. 44, n. 2, p. 524-527, 1979.

[10] ESTEVES, W.; BARRERAARELLANO, D., NUNES, M. L., GALVÃO, M. T. E. L., ANTONIASSI, R. Composição de ácidos graxos e triglicerídeos de quatro cultivares de cacau. Cienc. Tecnol. Aliment., v. 14, n. 2, p. 247-252, 1994.

[11] FAO/WHO. Food and Agriculture Organization/World Health Organization. Report for a joint FAO/WHO Expert Consultation on Protien Quality Evaluation, Bethesda, Maryland, 1990.

[12] GAHAN, P. B. Plant histochemistry and cytochemistry an Introduction. Academic Press, New York, 1984. 
[13] HACISEFEROGULlARE, H.; GEZER, I.; BAHTIYARCA, Y.; MENGES, H. O. Determination of some chemical and physical properties of Sakiz faba bean (Vicia faba L. Var. Major). J. Food Eng., v. 60, n. 4, p. 475-479, 2003.

[14] HARTMAN, B. L.; LAGO, R. C. A. Rapid preparation of fatty acid methylesters from lipids. Laboratory Prac., v. 22 , n. 7, p. 475-476, 1973.

[15] ISHOlA, M. M.; AGBAJI, E. B.; ABGAJI, A. S. A. A chemical study of Tamarindus indica (Tsamiya) fruits grown in Nigeria. J. Sci. Food Agric., v. 51, n. 1, p. 141143, 1990.

[16] JUNQUEIRA, R. G.; SGARBIERI, V. C. Isolation and general properties of lectins from the bean (Phaseolus vulgaris, Var. Rosinha G2). J. Food Biochem., v. 5, n. 3, p. 165-179, 1981.

[17] KAKADE, M. L.; RACKIS, J. J.; McGHEE, J. E.; PUSKI, G. Determination of trypsin inhibitor activity of soy products: a collaborative analysis of an improved procedure. Cereal Chem., v. 51, n. 3, p. 376-382, 1974.

[18] KATARIA, A.; CHAUHAN, B. M.; GANDHI, S. Effect of domestic processing and cooking on the antinutrients of black gram. Food Chem., v. 30, n. 2, p. 149-156, 1988.

[19] KATARIA, A.; CHAUHAN, B. M.; PUNIA, D. Antinutrients and protein digestibility (in vitro) of Mung bean as affected by domestic processing and cooking. Food Chem., v. 32, n. 1, p. 9-17, 1989.

[20] LIMA, D. U.; OLIVEIRA, R. C.; BUCKERIDGE, M. S. Seed storage hemicelluloses as wet-end additives in papermaking. Carbohydrate Polymers, v. 52, n. 4, p. 367-373, 2003.

[21] O'BRIEN, T. P.; McCully, M. E. The Study of Plant Structure. Principles and Selected Methods. Termarcarphi Pty, Melbourne (1981).

[22] OMOGBAI, F. E. Lipid composition of tropical seeds used in the Nigerian Diet. J. Sci. Food Agric., v. 50, n. 2, p. 253-255, 1990.

[23] ORTEGA-NIEBLAS, M.; VÁSQUEZ-MORENO, L.; ROBLES-BURGUEÑO, M. R.. Protein quality and antinutritional factors of wild legumes seeds from the Sonoran Desert. J. Agric. Food C hem., v. 44, n. 10, p. 3130-3132, 1996.

[24] PROSKY, L.; ASP, N. G.; FURDA, I.; DEVRIES, J. W.; SCHWEIZER, T. F.; HARLAND, B. F. Determination of total dietary fiber in foods and food products. Collaborative study. J Assoc. of. Anal. Chem., v. 62, n. 4, p. 677-679, 1985.

[25] REDDY, N. R., PIERSON, M. D., SATHE, S. K., SALUNKE, D. K. Chemical nutritional and physicological aspects of dry bean carbohydrates: a review, Food Chem., v. 13, n. 1, p. $25-68,1984$.

[26] REID, J. S. G.; EDWARDS, M. E. Galactomannans and other cell wall storage polysaccharides in seeds. Stephen A. L. (Ed.) Food polysaccharides and their applications. Marcel Dekker. Inc. NewYork, p. 155-186, 1995.
[27] SATHE, S. K. The nutritional value of selected Asiatic pulses: chickpea, black gram, mung bean and pigeon pea. Nwokolo, E. \& Smartt, J. (Ed.) Food and Feed from Legumes and Oilseeds, Chapman $\&$ Hall, London, p. 1232, 1996.

[28] SCHERBUKHIN, V. D.; ANUlOV, O. V. Legume seed galactomannans (Review). Applied Biochem. Microb., v. 35, n. 3, p. 229-244, 1999.

[29] SILVA, M. R.; SILVA, M. S.; MARTINS, K. A.; BORGES, S. Utilização tecnológica dos frutos de jatobá-do-cerrado e de jatobá-da-mata na elaboração de biscoitos fontes de fibra alimentar e isentos de açúcares. Ciênc. Tecnol. Aliment., v. 21, n. 2, p. 176-182, 2001.

[30] SILVA, M. R.; SILVA, M. A. A. P.; CHANG, Y. K. Utilização da farinha de jatobá (Hymenaea stigonocarpa Mart.) na elaboração de biscoitos tipo cookie e avaliação de aceitação por testes sensoriais afetivos univariados e multivariados. Ciênc. Tecnol. Aliment., v. 18, n. 1, 1998.

[31] SNYDER, H. E.; KWON, T. W. Soybean utilization. AVI Book, New York, 346p. (1987).

[32] SOTELO, A. The nutritive value of wild Mexican legumes with a potential for nutritional use. Nwokolo, E. \& Smartt, J. (Ed.) Food and Feed from Legumes and Oilseeds, Chapman \& Hall, London, p. 33-48, 1996.

[33] SOTELO, A.; ADSUlE, R. N. Chickpea (Cicer arietinum L.). Nwokolo, E. \& Smartt, J. (Ed.) Food and Feed from Legumes and Oilseeds, Chapman \& Hall, London, p. 8289, 1996.

[34] SOTElO, A.; SOUSA, H.; SANCHEZ, M. Comparative study of the chemical composition of wild and cultivated beans (Phaseolus vulgaris). Plant Foods Human Nutr., v. 47, n. 2, p. 93-100, 1995.

[35] TOGASHI, M.; SGARBIERI, V.C. Caracterização química parcial do fruto do barú (Dypterix alata, Vog). Ciênc. Tecnol Aliment., v. 14, n. 1, p. 85-95, 1994.

[36] UKhun, M. E.; IFEBIGH, E. O. Chemical Analysis of Centrosema pubescence legume seeds. J. Food Biochem., v. 12, n. 4, p. 261-267, 1989.

[37] UKHUN, M. E.; IFEBIGH, E. O. Compositional chemistry of Cassia alata seeds. Food Chem., v. 30, n. 3, p. 205$210,1988$.

[38] VADIVEL, V.; JANARDHANAN, K. Nutritional and antinutritional attributes of the under-utilized legume, Cassia floribunda Cav. Food Chem., v. 73, n. 2, p. 209215, 2001.

\section{6 - AGRADECIMENTOS}

Ao programa PIBIC/CNPq pela bolsa de iniciação cientifica da autora T. G. Matuda. As autoras agradecem a Prof ${ }^{\mathrm{a}} \operatorname{Dr}^{\mathrm{a}}$ Débora de Queiroz Tavares pelo auxílio na análise da microestrutura das sementes. 